\title{
Rheological Behavior of Drilling Muds, Characterization Using MRI Visualization
}

\author{
P. Coussot ${ }^{1}$, F. Bertrand ${ }^{1}$ and B. Herzhaft ${ }^{2}$ \\ 1 Laboratoire des matériaux et des structures du génie civil (LMSGC) 2, Allée Kepler, \\ 77240 Champs-sur-Marne - France \\ 2 Institut français du pétrole, 1 et 4, avenue de Bois-Préau, 92852 Rueil-Malmaison Cedex - France \\ e-mail: philippe.coussot@lcpc.fr - francois.bertrand@univ-mlv.fr - benjamin.herzhaff@ifp.fr
}

\begin{abstract}
Résumé - Visualisation par IRM du comportement rhéologique des boues de forage — Les boues de forage sont des fluides complexes utilisés pour le forage des puits pétroliers. Le rôle des fluides de forage est multiple : transporter les déblais rocheux jusqu'à la surface, maintenir une pression au droit de la formation rocheuse, lubrifier et refroidir l'outil. Il y a principalement deux familles de boues de forage : les boues à base d'huile (émulsions inverses de saumure dans une phase huile avec de nombreux additifs) et les boues à base d'eau (solutions aqueuses d'argiles et de polymères). Les formulations de boues à base d'huile ont beaucoup évolué et sont des formulations très complexes comprenant de nombreux additifs. L'huile de base peut être de différente nature et les additifs sont variés : gouttelettes de saumure, tensioactifs, argiles organophiles, viscosifiants, divers solides, etc. Ces additifs donnent aux boues des propriétés rhéologiques particulières. Les boues de forage sont souvent décrites comme des fluides rhéofuidifiants et thixotropes à seuil. Du fait de leur composition complexe, les boues de forage ont une structure interne qui est susceptible de se modifier selon les conditions d'écoulement et/ou de cisaillement, pouvant mener à des phénomènes non homogènes au sein du matériau. Il est donc intéressant de développer des techniques d'investigation permettant de visualiser la structure du fluide parallèlement à une mesure rhéologique.

Dans cet article, nous présentons des résultats de mesures rhéologiques couplées à de l'imagerie par résonance magnétique (IRM). Avec cette technique, il est possible de déterminer le profil de vitesse du fluide dans un écoulement viscométrique. Des mesures rhéologiques conventionnelles réalisées sur deux formulations de fluides de forage donnent des courbes d'écoulement similaires : au-dessus d'un gradient critique, elles présentent une comportement rhéofluidifiant avec seuil d'écoulement apparent, en dessous de ce gradient critique, on observe un comportement visqueux simple sans seuil d'écoulement. L'utilisation de l'IRM montre qu'en fait, en dessous de ce gradient critique, un écoulement stable n'est pas possible, la déformation se localise dans une zone dont la dimension peut dépendre de la taille des éléments constitutifs. Le comportement rhéologique apparent observé lors des mesures rhéologiques conventionnelles est donc la signature de cette zone cisaillée et ne représente pas le comportement du matériau dans son ensemble.
\end{abstract}

\footnotetext{
Abstract - Rheological Behavior of Drilling Muds, Characterization Using MRI Visualization Drilling muds are very complex fluids used to drill oil wells; their functions are various: to carry the rock cuttings to the surface, to maintain a sufficient pressure against the rock formation, to lubricate and cool the bit. There are mainly two families of drilling muds: oil based muds (invert emulsion of brine into an oil phase with various additives) and water based muds (aqueous solutions of clays and polymers). Originally prepared from produced oil, oil based muds formulations have evolved to very complex compositions of
} 
various additives. The base oil may be of various nature, and additives are very complex: water droplets, surfactants, organophilic clays, viscosifyers, various solids and others. These additives give specific properties to the mud, particularly regarding rheological properties. Drilling muds are often described as thixotropic shear thinning fluids with a yield stress. Due to their complex composition, drilling muds exhibit an internal structure which is liable to modify according to the flowing and shear conditions, which may lead to non homogenous phenomena. It is therefore important to develop investigation techniques allowing to visualize the internal structure of the fluid in parallel to rheological measurements.

In this study, we present rheological experiments coupled to magnetic resonance imaging (MRI). Using this technique, it is possible to determine the velocity profile in a viscometric flow. Conventional rheological experiments performed on two different drilling fluids formulations give similar flow curves: beyond a critical apparent shear rate there is a simple yielding behavior with an apparent plateau at low shear rates; below this critical shear rate there is a simple viscous behavior without yield stress. MRI experiments show that in fact, below this critical shear rate, no stable flow can occur and the deformation is localized in a region of the sample the dimensions of which may depend on the size of the constitutive elements. The (macroscopic) rheological behavior observed from conventional rheometric experiments is then the signature of this sheared zone and does not represent the behavior of the bulk material.

\section{INTRODUCTION}

Oil well drilling operation is part of the global process implemented to localize and extract from the reservoir the hydrocarbons lying underground. Several wells are necessary to exploit an oilfield: exploration wells to confirm the presence of oil, evaluation wells to estimate the economic viability of the project and development wells which lead to the production of the field. The classical drilling technique is the rotary drilling technique, invented at the beginning of the $20^{\text {th }}$ century by Lucas for a drilling operation in Texas [1]. This technique consists in applying a weight on a bit which is put on rotation through drill pipes string. With the combined effect of the weight and the rotation, the drill bit cut the rock producing a certain amount of rock cuttings. These cuttings are then lifted off to the surface thanks to a fluid which is circulated downward through the drill pipe and upward through the annular space between the rock and the pipe. Tubings are added as the drilling goes deeper and when a certain length has been drilled, a steel casing is sealed into the bore-hole with cement. Drilling operation can continue with a lower diameter.

Drilling fluids that are used may be classified as "complex fluids" due to their nature (these fluids may be emulsion/ suspensions of various constituents) and to their specific rheological properties. These fluids, called "drilling muds" are classically shear thinning, thixotropic and strongly thermal dependent. Their internal structure may be very complex and is liable to modify depending on the flowing and shear conditions, which may lead to non homogenous phenomena. Characterization of the internal structure of the fluid in parallel to rheological measurement is therefore very important. In particular, low shear rate rheology may have a strong effect on some drilling characteristics such as cuttings removal or barite sag. Barite sag is the rapid sedimentation of the heavy solid particles which are used as weighting particles in the formulation. This phenomenon occurs mainly in high angle drilling situations and may lead to catastrophic situations. A better comprehension of the low shear rate characteristics of the muds could help in understanding and controlling these solid carrying problems.

After a brief introduction on drilling muds, we present here results of a collaborative study between IFP and $L M S G C$ aiming at visualizing the velocity field of the sheared fluid with magnetic resonance imaging in parallel to rheological measurement. Conventional rheometrical measurements have been performed on two drilling mud formulations (water based and oil based) with a particular attention to low stress behavior. The corresponding results are then analysed with regards to MRI velocity profiles obtained under similar conditions, which show that no stable flow can occur below a critical shear in the mud sample.

\section{FUNCTION AND COMPOSITION OF DRILLING MUDS}

\subsection{Drilling Muds Functions}

Drilling muds fulfill several purposes for the drilling operation. First the circulation of a viscous mud allows to evacuate rock cuttings from the bottom hole to the surface, where the solids are separated from the fluid.

Muds also maintain the cuttings in suspension when the circulation is stopped: indeed, in order to add tubings to the drill string, the fluid circulation is regularly stopped. During this rest time, solid cuttings may sediment to the bottom hole and lead to plugging of the well. Drilling muds are therefore thixotropic and develop a gel when not circulated. 
The fluid circulated will generate a certain pressure (addition of the hydrostatic and the frictional pressure) which is maintained at a value superior to the pressure of the rock formation (in overbalanced drilling conditions). This helps to maintain the well walls, to prevent destabilization of the ground and to control the venue of fluids from the formation. Due to this pressure difference, the mud will filtrate in the permeable rock formation and will form a filtration cake at the wall. Finally, the circulation of the mud helps to cool down and lubricate the drill bit.

\subsection{Drilling Muds compositions}

Drilling muds may be classified in three families:

- Water based muds are principally aqueous solutions of polymers and clays in brines with different types of solids and additives.

- Oil based muds are invert emulsions of brine into an oil phase stabilized by surfactants. various additives are added as organophilic polymers, organophilic surface modified clays, solids and other additives.

- Underbalanced fluids are used for a specific drilling technique called underbalanced drilling where the pressure in the drilling fluid is lower than the pore pressure of the rock formation. These fluids may be gas, aerated muds (classical muds with nitrogen) or aqueous foams.

The choice of the mud formulation will depend on the nature of the rock formation, the environmental and economic constraints as well as the possibility of supplying on site. Different formulations may be used for a same drilling operation depending on the geological nature of the different layers drilled. Oil based Muds can give better performances but are generally more expensive and less ecologically friendly.

Numerous additives are added to the formulation in order to reach specific purposes which are sometimes contradictory. For example, muds have to be viscous in order to be able to lift the cuttings to the surface, but at the same time, viscosity must not be too high in order to minimize friction pressure loss. Additives can be for example viscosifiers (clays, polymers as PAC (Polyanionique Cellulose), HEC (Hydroxy Ethyl Cellulose), xanthan gum, guar), weighting agents (barytine, carbonate), filtrate reducers (starch, CMC (Carboxy Methyl Cellulose), resins), clays swelling inhibitors $(\mathrm{KCl}$, glycol), plugging agent for mud losses.

\section{MATERIALS AND METHODS}

\subsection{Drilling Muds}

Two different drilling muds have been prepared for this study. The first one is a water based mud which is mainly an aqueous solution of bentonite and polymers. Its composition is given in the Table 1 .
TABLE 1

\begin{tabular}{c|c}
\hline Product & Concentration (g/l) \\
\hline Bentonite clay & 30 \\
Viscosifying polymer A & 2.5 \\
Viscosifying polymer B & 3 \\
Dispersing agent & 5 \\
$\mathrm{NaCl}$ & 30 \\
\hline
\end{tabular}

The second drilling mud is an oil based mud which composition is given in Table 2 .

TABLE 2

\begin{tabular}{c|c}
\hline Product & Concentration $(\mathbf{g} / \mathbf{l})$ \\
\hline Dearomatized oil & 470.7 \\
Filtrate reducer & 6 \\
Emulsifier & 18 \\
Wetting agent & 2.94 \\
Lime & 20 \\
Organophilic clay & 15 \\
Viscosifyer & 4.04 \\
Brine & 322.5 \\
\hline
\end{tabular}

\subsection{Procedures}

For the conventional rheometry we used a Bohlin C/VOR rheometer with a cone and plate geometry (angle: $4^{\circ}$; diameter: $4 \mathrm{~cm}$ ) with smooth surfaces. We also carried out tests with parallel disks with smooth and rough surfaces: similar trends as described below were observed for both surface types. The material was set up then presheared at an apparent shear rate of $300 \mathrm{~s}^{-1}$ during $20 \mathrm{~s}$ and left at rest for $15 \mathrm{~s}$. Then a fixed level of stress was applied during a time ranging from 40 to $400 \mathrm{~s}$. After that the material was prepared again in the same way and submitted to another stress level. It was checked during the preshear that the boundary conditions and the material did not change significantly between each creep test by comparing the apparent viscosity during preshear.

As a "MRI-rheometer" we used a set-up and procedures described in details in [2]. Here we only recall the main aspects. We used a vertical coaxial cylinder geometry (inner cylinder radius: $r_{i}=4 \mathrm{~cm}$, outer cylinder of radius $r_{e}=6 \mathrm{~cm}$; length: $h=11 \mathrm{~cm}$ ). The surfaces of the outer and inner cylinder in contact with the fluid were covered with a sand-paper with an equivalent roughness of $200 \mu \mathrm{m}$. The rotation velocity of the inner cylinder is controlled and can be varied over a wide range but almost complete information concerning the fluid behavior can be obtained from tests at a rate in the range [1-100 rpm]. The temperature of the material in the Couette geometry could not be controlled but the room 
temperature was kept between 20 and $24^{\circ}$ (as for the tests with the laboratory rheometer). MRI was performed with a Bruker (France) set-up equipped with a vertical $0.5 \mathrm{~T}$ (Tesla) magnet (Magnex Scientific Ltd, United Kingdom) fitted with shielded gradients leaving a free bore of $25.5 \mathrm{~cm}$ and delivering a gradient of $50 \mathrm{mT} / \mathrm{m}$ with a rise time of $500 \mu \mathrm{s}$. The signal was collected within a linear birdcage coil of $24 \mathrm{~cm}$ length and $20 \mathrm{~cm}$ diameter. We used a sequence derived from that of [3]: a 1D acquisition was carried out with a single spin-echo sequence where $180^{\circ} \mathrm{RF}$ (Radio Frequency) selectivity was moved from the slice selection axis to another axis in order to select a rectangular volume of interest and enhance signal to noise by accumulation. The parameters used for both materials were TR (minimum repetition time): $1 \mathrm{~s}$ and TE (spin-echo duration time): $10.53 \mathrm{~ms}$. The volume imaged was a (virtual) rectangular portion of $20 \mathrm{~mm}$ in the axial direction with a width (in the tangential direction) of $5 \mathrm{~mm}$ and a length of 70 $\mathrm{mm}$ (in the radial direction, starting from the central axis) but only velocity data from the rheometer gap (filled with sample) are relevant and presented here. This volume was situated at the magnet center (so as to damp the effects of field heterogeneities) and sufficiently far from the bottom and the free surface of the rheometer for flow perturbations due to edge effects to remain negligible (this could be checked by velocity imaging at different depths in the fluid). This approach has been validated from tests with materials rotating as a plug within a single, rotating cylinder, and from tests with a Newtonian fluid [2]. The spatial resolution of our measurements is $0.5 \mathrm{~mm}$.

Just after its insertion between the cylinders the material was presheared at a rotation velocity of $80 \mathrm{rpm}$ during $10 \mathrm{~min}$. Then, with or without a preliminary rest, the rotation velocity was changed (in few seconds) to a given value and NMR signal was collected. Successive, elementary, velocity profiles were obtained every $8 \mathrm{~s}$ for the oil based mud and $64 \mathrm{~s}$ for the water based mud, leading to respective total times of acquisition for 128 elementary profiles of $18 \mathrm{~min}$ and $2 \mathrm{~h} 17 \mathrm{~min}$. Limitations and possible artefacts concerning tests with bentonite suspensions were discussed in [2], whose main conclusions apply for the present materials. A critical point here concerns the possibility of the development of fluid heterogeneities during flow. Note that these effects can hardly be detected from usual density imaging. However, if density heterogeneity developed, it should affect the velocity profile in time, especially just after flow start up. Here no significant variation in time of the successive velocity profiles was apparent, i.e. within our time resolution the difference observed between two elementary profiles can be attributed to measurement noise.

\section{RESULTS AND DISCUSSION}

Results from creep tests are presented in Figure 1 for oil based mud (a) and water based mud (b). For both materials the apparent shear rate follows different evolutions depending on the applied stress. For a stress below a critical value it progressively decreases in time: for the oil based mud the shear rate eventually reaches an apparent plateau after several tenths of seconds; for the water based mud it goes on decreasing significantly even after several hundreds of seconds. For a stress beyond this critical value the apparent shear rate increases first then tends to reach a plateau after few seconds. These
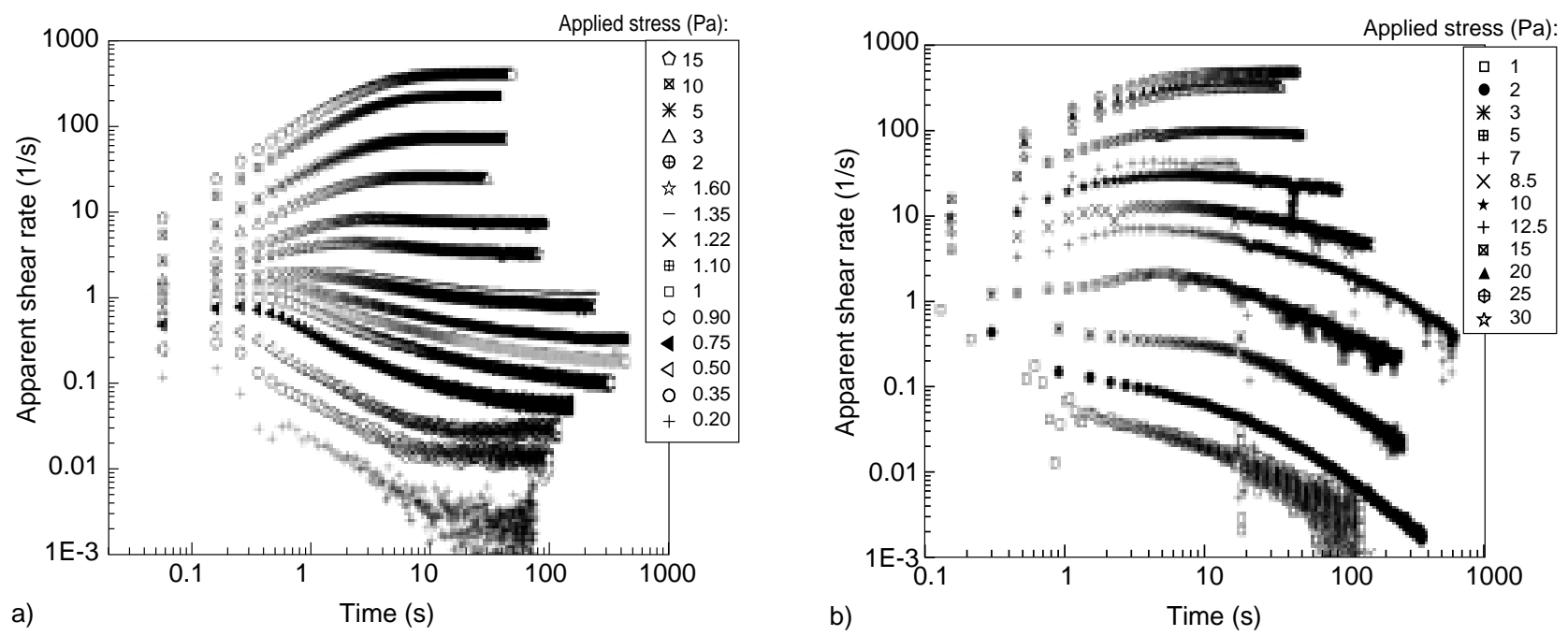

Figure 1

Creep tests under different stress values with the (a) oil based mud, and (b) the water based mud: shear rate as a function of time. 
trends are similar to those observed for various pasty materials exhibiting an apparent yield stress [4]. It thus seems that the flows of such materials can hardly reach a stable situation when the stress is smaller than a critical value, this fact being extremely clear with the water based mud.

This differs from the usual view on this subject: the flow curve of yield stress fluids is often determined from a more or less rapid increase or decrease of the applied stress, from which one finds that a Herschel-Bulkley model can correctly represent the behavior in a wide range of shear rates. According to this modeling the steady-state flow should have been reached before the time corresponding to the end of our creep tests. For every shear stress applied, let us note the value of the apparent shear rate at that time and plot in a diagram the corresponding shear stress $v s$ shear rate data: we find the apparent flow curves presented in Figure 2. For both materials they are composed of two main parts: beyond a critical apparent shear rate they have a simple yielding behavior similar to an ideal yield stress fluid (with an apparent plateau at low shear rates and a quasi newtonian behavior at high shear rate); below this critical shear rate they seem to have a simple viscous behavior without yield stress. Similar (apparent) flow curves have been obtained on oil based muds with different rheometers in IFP as well as in the Laboratoire de rhéologie in Brest [5] with similar values of critical shear rates.

At first sight these results are troublesome. Indeed they agree with the Barnes concept [6] which denies the existence of yield stress considering that the paste may flow with a high viscosity at low stresses, whereas these pastes are in practice clearly capable to support a load without yielding for an indefinite time. MRI-rheometry data appear to bring some interesting elements in this debate. The results in terms of steady-state velocity profiles are presented in Figure 3. In logarithmic scale, the velocity profiles for different rotation velocities of the inner cylinder have all the same aspect and they can be well represented by a truncated power-law model, which expresses as:

$$
\begin{gathered}
\tau<\tau_{c} \Rightarrow \dot{\gamma}=0 \\
\tau \geq \tau_{c} \Rightarrow \tau=k \dot{\gamma}^{n}
\end{gathered}
$$

in which $k$ and $n$ are two material parameters. Note that the second equation may also be written:

$$
\frac{\tau}{\tau_{c}}=\left(\frac{\dot{\gamma}}{\dot{\gamma}_{c}}\right)^{n}
$$

in which $\tau_{c}$ and $\dot{\gamma}_{c}$ are respectively the critical stress and shear rate below which the fluid cannot flow steadily. For such a material the velocity profile expresses as:

$$
v(r)=\alpha\left[\left(\frac{r}{R_{c}}\right)^{-m}-\left(\frac{r}{R_{c}}\right)\right]
$$

where $R_{c}$ is the radius associated to the interface between the sheared and unsheared regions and $m=(2 / n)-1$. It may be checked that the shear stress-shear rate relation deduced from (4) by using the theoretical shear rate $\left(\dot{\gamma}_{c}=r \partial(v / r) / \partial r\right)$ and shear stress $\left(\tau \propto 1 / r^{2}\right)$ distributions in a Couette system, corresponds to a constitutive equation
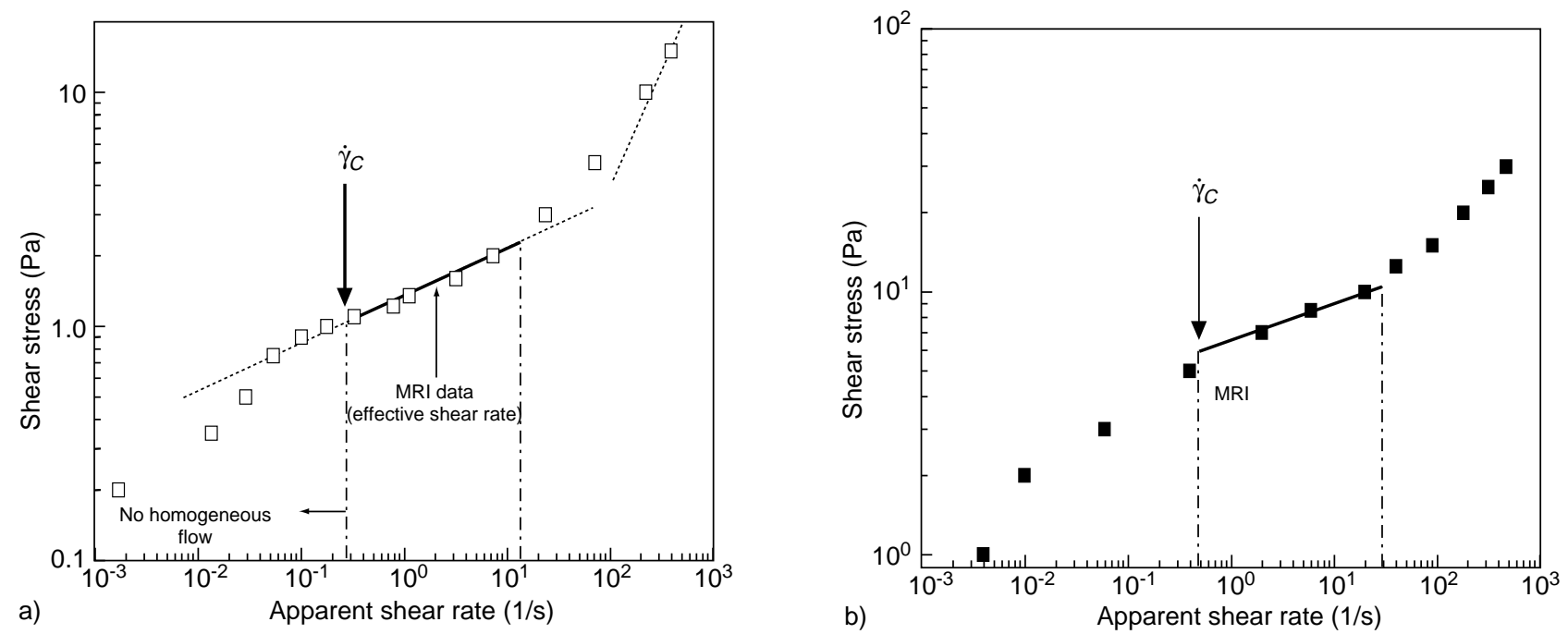

Figure 2

Apparent flow curves as determined by using the stress $v s$ shear rate data at the end of the creep tests presented in Figure 1: (a) oil based mud; (b) water based mud. The MRI data, represented by the model fitted to data, are shown in the form of a continuous, dark line. 

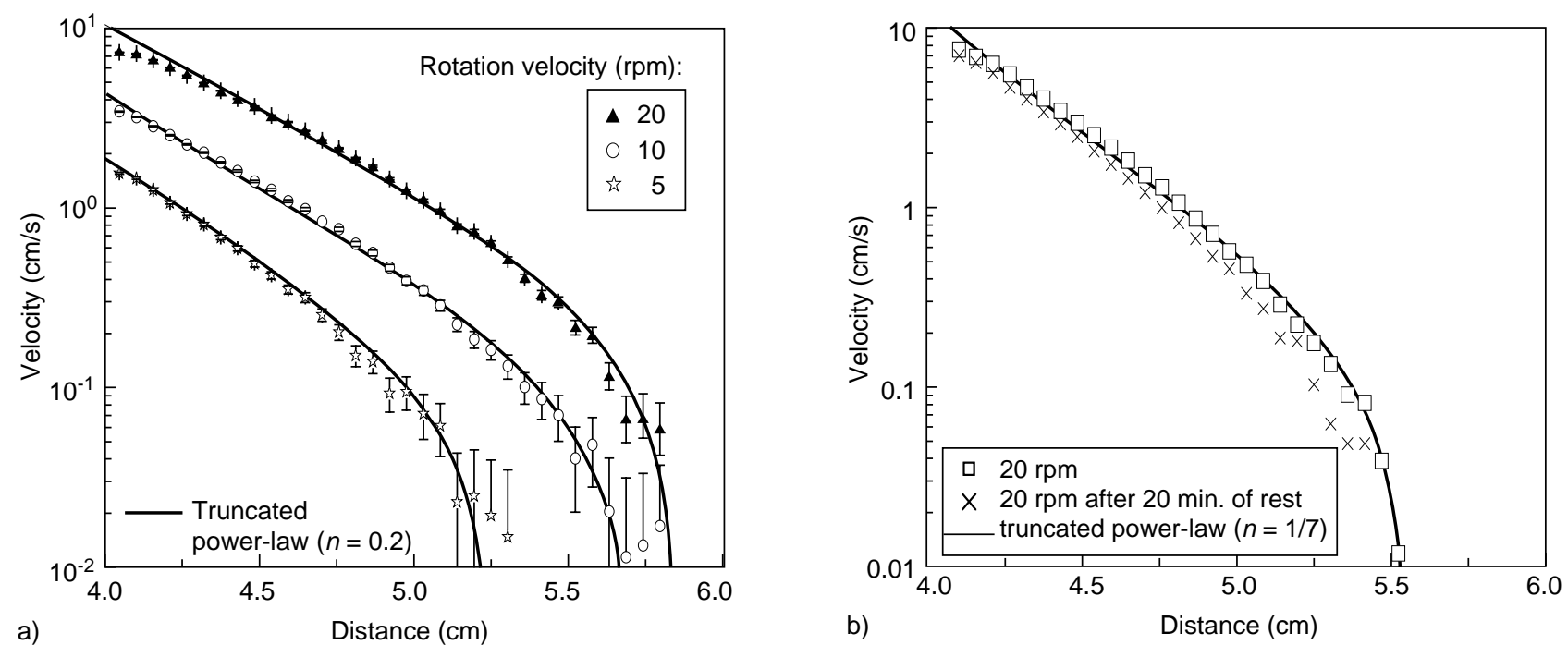

Figure 3

Velocity profiles as determined by MRI in a Couette system under different imposed rotation velocities for (a) the oil based mud and (b) the water based mud.
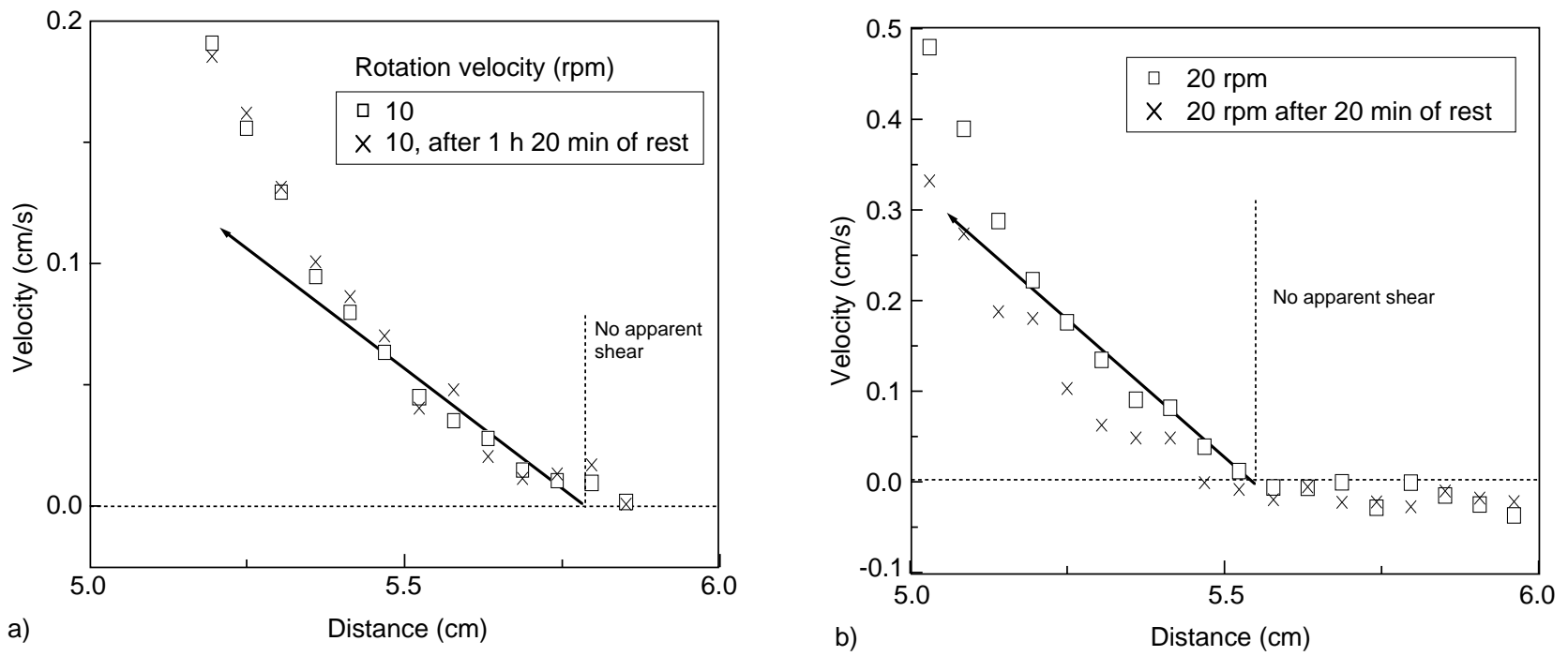

Figure 4

Velocity profiles of Figure 3 at a smaller scale in order to observe the discontinuity in shear rate at the transition between the solid and the liquid phases for (a) the oil based mud and (b) the water based mud.

of the type (3). Note that the parameters are linked by the relation:

$$
\dot{\gamma}_{c}=\alpha(m+1) / R_{c}
$$

In practice, we fitted such a velocity profile to our data and thus determined the parameters of the constitutive Equations $(1,2)$. It has been demonstrated elsewhere [7] that, when such a model can be well fitted to a MRI velocity profile over two or three decades of velocities, a Herschel-Bulkley model cannot represent the same data correctly: there necessarily remains a strong discrepancy between this model and the data either at high or low velocities, whatever the chosen parameters. This mainly comes from the fact that, as clearly appears from Figure 4, the velocity profiles have a slope rupture at the approach of the abscissa axis: the local shear rate remains 
almost constant over $5 \mathrm{~mm}$ then drops to zero as the tangential velocity reaches zero within the uncertainty of our experiments. In such a frame only a model like for example $(1,2)$ predicting a shear rate discontinuity at a critical stress seems capable to represent the behavior, and not a Herschel-Bulkley model, which predicts that the shear rate continuously decreases to zero as the shear stress tends to the yield stress.

Now, let us compare the results obtained from MRI with those obtained from conventional rheometry: MRI data predicts that the fluid may be represented by a power-law model at least up to a certain shear rate (see Table 3) but that below $\dot{\gamma}_{c}$ no stable flow can occur. This is precisely what we obtained from creep tests and the critical shear rates obtained by the two techniques almost exactly coincide (see Fig. 2). For the water based mud the results are perfectly consistent: in creep tests, below a critical stress, the material tends to completely stop flowing, in agreement with MRI data which correspond to steady state. For the oil based mud it is likely that at stresses below the critical value a more or less stable localization of shear, close to the wall, sets up, which leads to an apparent plateau of shear rate in time. However in that case the flowing material significantly differs from the bulk material so that usual (macroscopic) rheometrical data are not relevant. Such an effect cannot occur in the MRI-rheometer since the imposed stress remains significantly larger as long as the rotation velocity makes it possible to shear a significant part of the material.

TABLE 3

\begin{tabular}{l|c|c}
\hline \multicolumn{1}{c|}{ Material } & Oil based mud & Water based mud \\
\hline Rotation velocity $(\mathrm{rpm})$ & 10 & 20 \\
$R_{c}(\mathrm{~cm})$ & 5.7 & 5.55 \\
$m$ & 10 & 13 \\
$n$ & $1 / 5$ & $1 / 7$ \\
$\alpha(\mathrm{cm} / \mathrm{s})$ & 0.13 & 0.18 \\
$\dot{\gamma}_{c}(1 / \mathrm{s})$ & 0.25 & 0.45 \\
\hline
\end{tabular}

\section{CONCLUSIONS}

The rheological behavior of two drilling muds (water based and oil based) have been studied using conventional rheometrical tests coupled with MRI/rheometrical characterizations. These experiments clearly show that the two drilling muds have similar characteristics: below a critical shear rate, they cannot reach a stable flow regime, when the imposed shear rate is lower than the critical one, the deformation is localized in a particular region of the sample and there is a shear rate discontinuity at the interface between the flowing and static regions. The macroscopic rheological behavior of the fluid (as obtained from conventional rheological experiments) is then the signature of the behavior of this particular sheared area and not of the whole sample. The behavior below the critical shear rate therefore should depend on the constitutive elements of the fluids, particularly when the size of the sheared area becomes of the order of magnitude of the size of the constitutive elements of the mud (particles, droplets, etc.). This will be investigated through future studies.

These results provide new insights into some drilling problems related to drilling muds, especially concerning the low shear rate regime. Further work will also focus on the implications of these data on the characteristics of flows of muds in annular geometries under various regimes.

\section{REFERENCES}

1 Nguyen J.P. (1993) Le forage, Éditions Technip, Paris.

2 Raynaud, J.S., Moucheront, P., Baudez, J.C., Bertrand, F., Guilbaud, J.P. and Coussot, P. (2002) Direct determination by NMR of the thixotropic and yielding behavior of suspensions. J. Rheol., 46, 709-732.

3 Hanlon, A.D., Gibbs, S.J., Hall, L.D., Haycock, D.E., Frith, W.J. and Ablett, S. (1998) Rapid MRI and velocimetry of cylindrical Couette flow. Magn. Reson. Imag., 16, 953961.

4 Coussot, P., Nguyen, Q.D., Huynh, H.T. and Bonn, D. (2002) Viscosity bifurcation in thixotropic, yielding fluids. J. Rheol., 46, 573-589.

Coussot, P., Nguyen, Q.D., Huynh, H.T. and Bonn, D. (2002) Avalanche behavior in yield stress fluids. Phys. Rev. Lett., 88, 175501.

Coussot, P., Raynaud, J.S., Bertrand, F., Moucheront, P. Guilbaud, J.P., Huynh, H.T., Jarny, S. and Lesueur, D. (2002) Coexistence of liquid and solid phases in flowing soft-glassy materials. Phys. Rev. Lett., 88, 218301.

5 Herzhaft, B., Rousseau, L., Neau, L., Moan, M., Bossard, F. (2003) Influence of Temperature and Clays/Emulsion Microstructure on Oil-Based Mud Low Shear Rate Rheology. Society of Petroleum Engineer Journa.

6 Barnes, H.A., and Walters, K. (1985) The yield stress myth? Rheologica Acta, 24, 323-326.

7 Jarny, S., and Coussot, P. (2002) Caractérisation des écoulements de pâte dans une géométrie Couette. Rhéologie, 2, 52-63. or distributed for profit or commercial advantage and that copies bear this notice and the full citation on the first page. Copyrights for components of this work owned by others than IFP must be honored. Abstracting with credit is permitted. To copy otherwise, to republish, to post on servers, or to redistribute to lists, requires prior specific permission and/or a fee. Request permission from Documentation, Institut français du pétrole, fax. +33147527078 , or revueogst@ifp.fr. 